\title{
Verbal learning dysfunction with combined centre median and amygdala lesions
}

\author{
M. F . J U R K O A N D O . J . A N D Y \\ From the University of Mississippi Medical Center, Department of Neurosurgery, Jackson, \\ Mississippi, USA
}

SUMMARY Stereotaxic lesions in either or both amygdala did not impair verbal learning ability (presented by ear as a paired-associates test). Centre median lesions alone did not impair this form of learning; however, when combined with a left amygdala lesion a significant decrease in scores occurred which persisted for up to two years after operation. The data support a hypothesis that medial thalamic structures have alerting functions in learning mechanisms.

Clinicians have long reported memory disturbances after not only major loss of tissue from the cerebral hemispheres but discrete lesions in the hippocampal-mammillary circuit and tumours of the floor of the third ventricle. In some patients these tumours involved thalamic structures (see case reports and literature reviews, Williams and Pennybaker, 1954; Victor et al., 1961; Barbizet, 1963; Drachman and Arbit, 1966). In seizure patients Penfield, Scoville and Milner found memory losses after temporal lobectomy which they describe as maximised with the more extensive resections of hippocampal tissue (see review of their long-term study, Milner, 1972). Gol and Faibish (1967), after resection and/or combined stereotaxic lesions of hippocampal tissue in patients with intractable pain, observed memory deficits which varied with the size of the lesion but, in addition, appeared to be more influenced by damage to the overlying neocortex of the temporal lobe than by the hippocampal lesions. They concluded (p. 397) that 'bilaterally extensive hippocampal lesions did not produce the extreme memory deficits described by Penfield, Scoville and Milner'. They suggested that 'memory recording' including acquisition and retention, cannot be assigned simply to one part of the nervous system, citing, for example, Wernicke's syndrome where a severe memory deficit is present yet most of the pathology is in the diencephalon and the hypothalamus rather than in the temporal lobe and hippocampal structures.

Address for reprint requests: Dr M. F. Jurko, University of Mississippi Medical Center, Department of Neurosurgery, 2500 North State Street, Jackson, Mississippi 39216, USA.

Accepted 4 February 1977
Earlier investigators (for example, Victor et al., 1961) had also concluded that memory loss is not simply related to the size of the lesion, but that small lesions located in specific portions of the brain, including subcortical areas such as the thalamus, are capable of interfering significantly with the functions of memory and of learning. Indeed, subsequent investigators did find that small stereotaxic lesions placed in certain areas of the thalamus, viz left ventrolateral thalamus and in the pulvinar, produced (verbal) memory deficits on formal tests (McFie, 1960; Krayenbühl et al., 1965; Perret et al., 1969; Ojemann et al., 1971). Electrical stimulation in these structures also impaired the memory mechanisms (Ojemann and Fedio, 1968; Fedio and Van Buren, 1975). In their study of learning after a stereotaxic lesion Jurko and Andy (1973) compared performance on a verbal paired associates learning test after lesions in the centre median nucleus with lesions located outside the centre median in the ventroposterolateral thalamus. Reduced scores were found postoperatively after the lateral thalamic lesions, whereas scores were increased (as would be expected with practice) after the centre median placements. The present study reports the effect on this verbal learning test of lesions placed in more than one brain structure and compares patient performance after amygdalotomy with performance after an additional lesion was made in the centre median nucleus.

\section{Method}

The findings were obtained from six patients who had lytic lesions placed in the brain for treatment of intractable seizures. Three patients had a left 
centre median lesion, and three patients a right centre median lesion placed after amygdalotomy in each instance. In the left thalamotomy group two patients had a previous bilateral amygdalotomy and one patient a unilateral amygdalotomy on the left side. In the right thalamotomy group one patient had a bilateral amygdalotomy and two patients a unilateral right amygdalotomy. The ages of patients in the group with right centre median lesions were 20,25 , and 27 years, and in the group with left centre median lesions they were 20,23 , and 38 years. All the patients were right handed. The same form (Form 1) of the Associate Learning Test, taken from the Wechsler Memory Scale (Wechsler, 1945), was used in preoperative and postoperative testing. This paired associates test requires the learning of 10 pairs of words in six easy (familiar) associations-for example, north-south-and four hard (unfamiliar) associations-for example, crush-dark. The subject was required to supply the associate (paired) word after aural presentation of the entire list. The highest possible score is 21 earned over three presentations of the word list.

\section{Results}

\section{AMYGDALOTOMY}

Unilateral amygdalotomy, on either the left or right side, did not impair the learning process (Figs. 1 and 2). The improvement which is usually observed with practice occurred as expected. The scores five days after the unilateral amygdala

Amygdalotomy and Left Thalomotomy Effects on Associates Learning
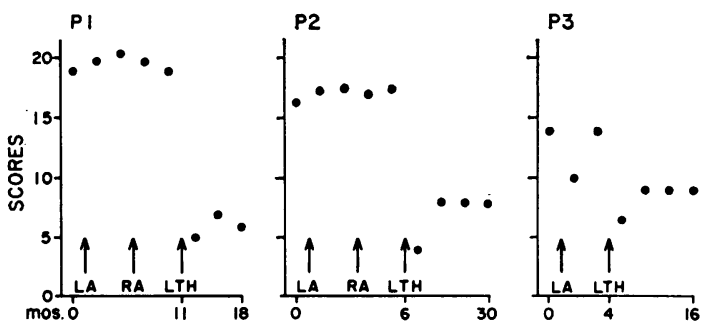

Fig. 1 Arrows indicate surgery points. LA left amygdalotomy; $R A$ right amygdalotomy; $L T H$ left thalamotomy. First dot on left for all patients represents test score several days before any surgical procedure; second dot after each operation five days postoperative score. Time between $L A$ and $R A$ for patient $P 1$ was one and a half months and for $P 2$ two months. For $P 1$ second dot from right, and for $P 2$ and $P 3$ third dot from right indicates the two months post LTH-score; end dot on right for PI and second dot from right for $P 2$ and $P 3$ are seven months post-LTH scores.
Amygdalotomy and Right Thalamotomy Effects on Associotes Learning
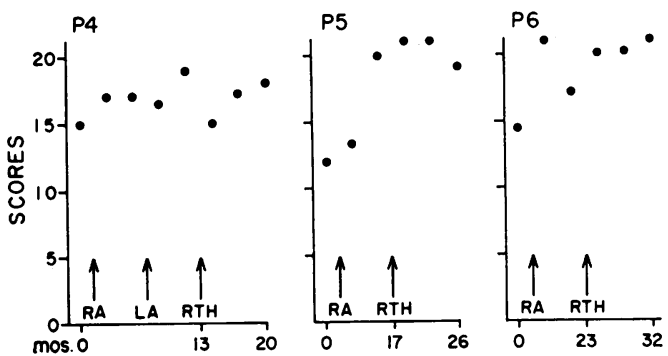

Fig. 2 Arrows indicate surgery points. $R A$ right amygdalotomy; LA left amygdalotomy; $R T H$ right thalamotomy. First dot on left represents test score several days before any surgical procedure. Second dot after each operation denotes five days postoperative score. Time between $R A$ and $L A$ for patient $P 4$ was six months. Second dot from right P4, P5, P6, denotes two months post-RTH score; end dots are the seven to nine months post-RTH scores.

lesions were higher in five of six patients (Sandler's $\mathrm{A}=0.198, \mathrm{P}<0.01$ ). Bilateral amygdalotomy also did not impair learning of the list (patients P1 and P2, (Fig. 1), and P4, (Fig. 2)). On the fifth day after bilateral amygdalotomy, scores remained higher than the scores before operation (Sandler's $\mathrm{A}=0.247, \mathrm{P}<0.05)$.

LEFT THALAMOTOMY COMBINED WITH AMYGDALOTOMY

In the left thalamotomy group there was a decrease in the associate learning scores in all patients who had undergone a previous amygdalotomy $(50 \%, 71 \%$, and $74 \%)$ when compared to the scores immediately before thalamotomy. It appears that the decrement of learning is greater when the left thalamotomy follows a bilateral amygdala lesion in contrast with a left amygdala lesion alone (compare scores of patients P1 and P2 with that of patient P3, Fig. 1). Learning impairment was greatest in the period immediately after left thalamotomy (compare the fifth postoperative day scores in patients $\mathbf{P} 1, \mathbf{P} 2$, and $\mathbf{P} 3$ (Fig. 1) with the subsequent scores). Although there was some improvement in follow-up scores, impairment persisted for up to two years postoperatively (P2, Fig. 1).

RIGHT THALAMOTOMY COMBINED WITH AMYGDALOTOMY

After amygdalotomy a right thalamotomy resulted in increased scores in two patients (P5 and P6, Fig. 2) of $5 \%$ and $18 \%$. In one patient (P4) there was a decrease of $21 \%$. The difference in 
postoperative scores between the left and right thalamotomy group was significant at the 0.05 level $(t=<3.49)$. In the group with a right centre median lesion the expected improvement due to learning effects was greater with unilateral than bilateral amygdalotomy (compare scores of patient P4 with patients P5 and P6, Fig. 2).

\section{Discussion}

Diminished ability for verbal learning on formal tests after the placement of a lesion in the centre median after a lesion in the amygdala is consistent with the views of previous clinical investigators who postulated that medial thalamic structures are vital components in memory circuitry (for example, Victor et al., 1961). The medial thalamic structures have been described as supplying an 'alerting' function and as contributing to multiple mental functions. These views come from reports of investigators such as Spiegel et al. (1955) who found that patients with stereotaxically placed lesions in the medial dorsal thalamus showed temporal disorientation in addition to a memory deficit for recent and past events, and a decreased responsiveness to sensory stimuli. These authors postulated that multiple neuronal circuits participate in a specific behavioural act, and this is supported by their case in which transient temporal disorientation after lesion of the dorsomedial nuclei of the thalamus reappeared several months later when the lesion was extended in a frontal direction to include the anterior nuclei-mammillary system. The recent work of Ojemann (1974) and Fedio and Van Buren (1975) using verbal and non-verbal tests appears to confirm an alerting function of medial thalamic structures. These investigators concluded that the medial thalamus and the 'non-specific' thalamic nuclei, such as the centre median and reticular nuclei, together facilitate orientation to stimulus cues anc direct attention to the verbal aspects of material presented in the external environment. Their data were interpreted as supporting an alerting mechanism operating in learning which labels or cues stimuli for their later retrieval. Also they feel that it is the left thalamus which evokes an alerting response that is specific for verbal aspects of stimulus handling, accelerating many higher mental processes, especially memory. Although the data in the present study support the contribution of medial thalamic structures to intact verbal skills, hemisphere dominance cannot be established firmly since cross-operative effectsthat is, right thalamotomy-left amygdalotomy, and vice versa-were not determined.
The comment of one of our patients indicates that the learning deficit which follows combined lesions of the amygdala and centre median involves deficiencies in data retrieval. The patient could not recall newly acquired telephone numbers unless the first two digits were given. This impaired handling of new information is underscored in the paired-associates test in which patients had difficulty producing the hard or unfamiliar word associations but had little or no difficulty with the easy or familiar associations.

From our data it appears that recovery from verbal learning deficits seen after amygdala-centre median lesions on the left side may be prolonged. There was essentially little improvement in the test scores at two and seven months, and the score of patient P2 at 24 months was the same as at two months after left thalamotomy. Blakemore and Falconer (1967) found that the paired associates learning deficit induced by unilateral left temporal lobectomy, which included extensive hippocampal removal, began to improve after the third postoperative year. By the fifth year the mean performance of the group returned to within the limits of its preoperative level. By the tenth year some patients even exceeded their preoperative performance. These investigators regard their results as showing the 'plasticity' of the brain, and also as indicating that other brain areas, yet unknown, have acquired through reorganisation the verbal learning functions formerly subserved by the dominant temporal lobe. Further studies on this aspect are required.

\section{References}

Barbizet, J. (1963). Defect of memorising of hippocampal-mammillary origin: a review. Journal of Neurology, Neurosurgery, and Psychiatry, 26, 127135.

Blakemore. C. B., and Falconer, M. A. (1967). Longterm effects of anterior temporal lobectomy on certain cognitive functions. Journal of Neurology, Neurosurgery, and Psychiatry, 30, 364-367.

Drachman, D. A., and Arbit, J. (1966). Memory and the hippocampal complex. Archives of Neurology (Chicago), 15, 52-61.

Fedio, P., and Van Buren, J. M. (1975). Memory and perceptual deficits during electrical stimulation in the left and right thalamus and parietal subcortex. Brain and Language, 2, 78-100.

Gol, A., and Faibish. G. M. (1967). Effects of human hippocampal ablation. Journal of Neurosurgery, 26, 390-398.

Jurko, M. F., and Andy, O. J. (1973). Psychological changes correlated with thalomotomy site. Journal of Neurology, Neurosurgery, and Psychiatry, 36, 846-852. 
Krayenbühl, H., Siegfried, J., Kohenof, M., and Yasargil, M. G. (1965). Is there a dominant thalamus? Confinia Neurologica, 26, 246-249.

McFie, J. (1960). Psychological effects of stereotaxic operations for relief of Parkinsonian symptoms. Journal of Mental Science, 106, 1512-1517.

Milner, B. (1972). Disorders of learning and memory after temporal lobe lesions in man. Clinical Neurosurgery, 19, 421-446.

Ojemann, G., and Fedio, P. (1968). Effect of stimulation of the human thalamus and parietal and temporal white matter on short-term memory. Journal of Neurosurgery, 29, 51-59.

Ojemann, G., Hoyenga, K. B., and Ward, A. (1971). Prediction of short-term verbal memory disturbance after ventrolateral thalomotomy. Journal of Neurosurgery, 35, 203-210.

Ojemann, G. A. (1974). Mental arithmetic during human thalamic stimulation. Neuropsychologia, 12, 1-10.
Perret, E., Kohenof, M., and Siegfried, J. (1969). Influences de lesions thalamiques unilaterales sur les fonctions intellectuelles, mnésiques et d'apprentissage de malades parkinsoniens. Neuropsychologia, 7, 79-88.

Spiegel, E. A., Wycis, H. T., Orchinik, C. W., and Freed, H. (1955). The thalamus and temporal orientation. Science, 121, 771-772.

Victor, M., Angevine, J. B., Mancall, E. L., and Fisher, C. M. (1961). Memory loss with lesions of the hippocampal formation. Archives of Neurology (Chicago), 5, 244-263.

Wechsler, D. (1945). Wechsler Memory Scale, Form 1. Psychological Corporation, New York.

Williams, M., and Pennybaker, J. (1954). Memory disturbance in third ventricle tumours. Journal of Neurology, Neurosurgery, and Psychiatry, 17, 115123. 